\title{
Contribuições da Pedagogia para se pensar as relações de saber e gênero na escola contemporânea
}

\section{Contributions of Pedagogy to think about knowledge and gender relationships in contemporary school}

\author{
Maria de Fátima de Andrade Ferreira ${ }^{1}$
}

\begin{abstract}
Resumo: O presente trabalho procura colocar em destaque as contribuições da Pedagogia para se pensar as relações de saber e gênero, sobretudo, nos ambientes de aprendizagens nos espaços da escola contemporânea e suas contradições com o projeto de emancipação, cidadania e educação em direitos humanos e o currículo escolar. O texto pretende contribuir para a reflexão sobre as relações de saber-poder (FOUCAULT, 2003a, 2003b) nos ambientes de aprendizagens nos espaços escolares, considerando que é imprescindível à instituição de uma formação cidadã e a atuação do professor-educador na construção de conhecimentos nos espaços de (re)construção de experiências do sujeito. Enfim, para modificar as concepções de gênero, práticas pedagógicas e práticas educativas, com atenção ao desenvolvimento de consciências, discursos, saberes, requer um olhar positivo sobre o aluno, uma posição do professor com autonomia pedagógica dentro da sala de aula e, nessa direção, buscar mecanismos de combate a preconceitos, discriminação e exclusão nas relações de gênero e suas intersecções com raça, etnia, classe social, escolarização e outros marcadores sociais na escola.
\end{abstract}

Palavras-chave: Pedagogia. Relações de gênero. Saber-poder na escolar.

\begin{abstract}
This article seeks to highlight the contributions of Pedagogy to think about knowledge and gender relations, especially in learning environments in contemporary school spaces and their contradictions with the emancipation project, citizenship and human rights education and the school curriculum. The text aims to contribute to reflect on knowledge-power (FOUCAULT, 2003a, 2003b) relationships in learning environment in the school spaces, considering that the institution of citizen training is fundamental the role of the techer-trainer in the construction of knowledge in the spaces of (re)construction of the subject's experiences'. Anyway, to modify gender concepts, pedagogical practices and educational practices, with attention to the development of consciences, speeches, knowledge, requires a positive view of the student and position of the teacher with pedagogical autonomy within the classroom and, in that sense, seek mechanisms to combat prejudice, discrimination and exclusion in gender relations and their intersection with race, ethnicity, social class, Schooling and other social markers in school.
\end{abstract}

\footnotetext{
${ }^{1}$ Doutorado em Educação e Pós-doutorado em Estudos Étnicos e Africanos pela Universidade Federal da Bahia UFBA. Professora Titular da Universidade Estadual do Sudoeste da Bahia - UESB. E-mail: mfatimauesb@hotmail.com Orcid: https://orcid.org/0000-0003-4094-6741
}

Sertanias: Revista de Ciências Humanas e Sociais - ISSN: 2763-566X Volume 1, número 1, julho-dezembro de 2020. 
Keywords: Pedagogy. Gender relations. Knowledge-power in school;

\section{Introdução}

O presente trabalho procura colocar em destaque as contribuições da Pedagogia para se pensar as relações de saber na escola contemporânea, sobretudo, nos ambientes de aprendizagens e suas contradições com o projeto de emancipação, cidadania e o currículo escolar.

Nessa perspectiva, pretende contribuir para a reflexão sobre relações de saber-poder na escola, considerando que é imprescindível à instituição de uma formação cidadão e a atuação do professor-educador na construção de saberes nos espaços de (re)construção de experiências do sujeito e o desenvolvimento de sua prática docente acerca das relações de gênero e suas intersecções com raça/etnia, no currículo e discursos veiculados na escola.

A pedagogia é a área do saber que se destina à formação do professor da educação infantil e séries iniciais do ensino fundamental, além da ocupação em diferentes setores de serviços educacionais, como por exemplo, a coordenação pedagógica e a gestão escolar. E, ao longo de décadas, sendo questionada sobre sua definição, conceitos, métodos, elementos que têm papel importante na constituição de saberes, cidadania, igualdade de oportunidades educacionais e justiça social. Na escola, as concepções de gênero e suas intersecções com raça/etnia, veiculadas no currículo, saberes e práticas docentes, têm um papel fundamental na formação do sujeito social. Porém, as contradições com o projeto de emancipação, cidadania, têm sido motivo de preocupação de pesquisadores de diferentes áreas do conhecimento.

O conceito de gênero, como afirma Louro (1997), é produzido no contexto histórico, social e político da sociedade, assim como os seus novos desdobramentos, por exemplo, as identidades de gênero e sexual, e o conceito se refere ao modo como as características sexuais são compreendidas, representadas e trazidas para a prática social e tomadas como parte do processo histórico.

As atuais mudanças econômicas, sociais, políticas, científicas, culturais e tecnológicas, ocorridas continuamente na sociedade e no mundo, têm influenciado diretamente a concepção e a organização das sociedades. E, consequentemente, afeta da educação, o currículo e a escola, como instituição destinada a ensinar e aprender a viver e estar no mundo, precisa ser um lugar

\footnotetext{
Sertanias: Revista de Ciências Humanas e Sociais - ISSN: 2763-566X Volume 1, número 1, julho-dezembro de 2020.
} 
de convivência humana e social, destinado à construção de saberes, cidadania e educação em direitos humanos.

Nesse contexto, a Pedagogia e a Educação tornam-se importantes campos de construção de saberes e conhecimento, que são campos e conceituações indissociáveis. Educação, termo complexo, com diferentes definições, e para se chegar ao seu sentido hoje, são apresentadas distintas descrições ao longo de sua construção (MARTINS, 2000). Não é de interesse aqui traçar este percurso de sua constituição e história, não cabe analisar neste texto, mas apresentar definições que se aproximam do objeto da pedagogia, seus objetivos e contribuições à formação do sujeito social, a partir da compreensão sobre relações de saber e de gênero nos ambientes de aprendizagens na escola. O compromisso de todos nós, professores (as), com essa questão é, sem dúvida, muito importante. Trata-se, sim, de vivermos uma nova realidade e de posicionarmo-nos criticamente diante dela. Para Carr (1988), uma educação-ação emancipatória é um processo que estimula os participantes a lutar por formas de educação mais justas, racionais, democráticas, participativas e plenas.

Libâneo (2001, p. 6) busca a concepção de Pedagogia como ciência da educação e define-a como "um campo de conhecimentos sobre a problemática educativa na sua totalidade e historicidade e, ao mesmo tempo, uma diretriz orientadora da ação educativa". Para Morin (2001, p. 13), é impressionante que a educação que visa "a transmitir conhecimentos seja cega quanto ao que é o conhecimento humano, seus dispositivos, enfermidades, dificuldades, tendências ao erro e à ilusão, e não se preocupe em fazer conhecer o que é conhecer”. É preciso combater as cegueiras do conhecimento e compreender que "todas as ciências rompem o velho dogma reducionista de explicação elementar: elas tratam de sistemas complexos onde as partes e o todo produzem e se organizam entre si” (MORIN, p. 27).

Em Saviani (2007), a pedagogia histórico-crítica exige interpretação e tem como fundamentos epistêmicos a teoria da educação. A educação é uma prática intencional no interior da sociedade, por isso, é preciso formular uma teoria da prática educativa. Que práticas pedagógicas podem superar desigualdades de gênero e suas intersecções com raça/etnia, classe social, na escola? Nessa perspectiva, este texto no tópico 2, tem como objetivo buscar uma breve compreensão sobre a Pedagogia e implicações ao longo de décadas sobre seu status de ciência e indissociabilidade entre Pedagogia e Educação, considerando a relevância de práticas educativas e práticas pedagógicas na construção de conhecimentos necessários à formação do

\section{Sertanias: Revista de Ciências Humanas e Sociais - ISSN: 2763-566X Volume 1, número 1, julho-dezembro de 2020.}


sujeito. No tópico 3, trata da Pedagogia, relações de saber e gênero na escola, recorrendo a Foucault (2003a, 2003b), Louro (1997), dentre outros.

Finalmente, para modificar as relações de saber-poder nos ambientes de aprendizagens nos espaços escolares, é imprescindível desenvolver concepções e práticas pedagógicas, com atenção ao desenvolvimento de consciências, discursos, saberes. Para tanto, exige um olhar positivo sobre o aluno, uma posição do professor com autonomia pedagógica dentro da sala de aula e buscar mecanismos de combate a preconceitos, discriminação e exclusão nas relações de gênero e suas intersecções com raça, etnia, classe social e outros marcadores sociais na escola.

\section{Pedagogia: um olhar sobre práticas educativas e pedagógicas e a formação do sujeito}

Pedagogia, vem ao longo de décadas, sendo questionada sobre seu conceito, concepção e definição e, por outro lado, acredita-se na importância dos saberes e conhecimentos da Pedagogia na construção de conhecimentos necessários à formação do sujeito social, sua cidadania e emancipação.

Nesse sentido, a docência, as práticas educativas e pedagógicas também são questionadas e exige-se novas conexões e confluências entre elas, considerando a importância desse engajamento no desenvolvimento dos processos de ensinar e aprender consciente, democrático, cidadão e autônomo.

Suchodolsky (1978) contribui com suas reflexões sobre a Pedagogia e as grandes correntes filosóficas e traz a relação e distinção entre a Pedagogia da Essência e a Pedagogia da Existência, contextualizando-as. $\mathrm{O}$ autor acompanha estas concepções pedagógicas fundamentais e os conflitos que ainda persistem na contemporaneidade, destacando transformações revolucionárias verificadas na sociedade e a educação para o futuro, situando a transição de uma concepção para a outra e as distinções entre seus defensores que, de um lado, defendem a evolução e, do outro, a adaptação. Martins (2000, p. 242) lembra que Suchodolsky (1978, p. 117), "propondo a superação das contradições, tanto da pedagogia da essência como da existência", chega à conclusão de que essa oposição filosófica não pode estar contida "numa pedagogia que aceite o estado das coisas existente".

A pedagogia não será respeitada senão por uma tendência que indique caminho do futuro, por uma pedagogia associada à atividade social que transforme esse estado de coisas e tenda a criar, para o homem, condições tais que sua existência possa tornarse a fonte e a matéria prima de sua essência $(1978$, p. 117).

\section{Sertanias: Revista de Ciências Humanas e Sociais - ISSN: 2763-566X Volume 1, número 1, julho-dezembro de 2020.}


Na visão de Martins (2000), as definições de educação, tanto de caráter individualista como aquelas que acentuam o caráter social, a exemplo de Kant (1724-1808), Durkheim (18581917) e outros, acabam reafirmando a "natureza axiológica e teleológica do educar pelos seus fins e seu produto, mas, ao passarem pelo crivo etimológico do termo mostram-se insuficientes à compreensão da complexidade do ato educativo, do educar e seus resultados” (p. 242). Trazendo diferentes definições para essa discussão, assim como, concepções e sentidos do termo educação, Martins (2000, p. 244) chega ao entendimento de que,

Anteve-se a complexidade contida no binômio educere-educare. Educação como 'educere' compreende a consideração do desenvolvimento do homem inteiramente, e não parcialmente tal como os contributos, por exemplo, da Sociologia, da Psicologia, ou seja, das ciências descritivas do desenvolvimento humano. Tal delimitação poderá reduzir excessivamente, a complexidade, e a fenomenologia do desenvolvimento humano e circunscreve-se operativamente à descrição das ciências humanas.

Em suas reflexões sobre como e de que modo buscar condições substantivas para aprender a viver, Morin (2001, p. 47) recorre a Durkheim (1890) para afirmar que, na educação, trata-se de transformar o conhecimento em sapiência, isso se orientando segundo as finalidades do aprender a viver por toda a vida e não podemos perder a sapiência do conhecimento.

Para Durkheim, o objetivo da educação não é o de transmitir conhecimentos sempre mais numerosos ao aluno, mas o "de criar nele um estado interior e profundo, uma espécie de polaridade de espírito que o oriente em um sentido definido, não apenas durante a infância, mas por toda a vida" (apud MORIN, 2001, p. 47). Para enfrentar estas dificuldades da compreensão sobre o aprender a viver, aprender as maiores lições da vida que é a compaixão pelo sofrimento de todos os humilhados e a verdadeira compreensão, entende que os objetivos do conhecimento são insuficientes para tanto e para compreender o ser subjetivo, o ser humano como sujeito.

Enfim, Morin recomenda que para enfrentar a dificuldade de compreensão humana exige-se recurso não a ensinamentos separados, mas a uma pedagogia conjunta que agrupe filósofo, psicólogo, sociólogo, historiador, escritor, que seria conjugada a uma iniciação à lucidez" (2001, p. 51). No dicionário de Filosofia, educação, do latim, educatio e,

Em geral, designa-se com esse termo a transmissão e o aprendizado das técnicas culturais, que são as técnicas de uso, produção e comportamento, mediante as quais, um grupo de homens é capaz de satisfazer suas necessidades, proteger-se contra a hostilidade do ambiente físico e biológico e trabalhar em conjunto, de modo mais ou menos ordenado e pacífico. Como o conjunto dessas técnicas se chama cultura [...], uma sociedade não pode sobreviver se sua cultura não é transmitida de geração para geração; as modalidades ou formas de realizar ou garantir essa transmissão chamamse educação (ABBAGNANO, 2000, p. 305).

\section{Sertanias: Revista de Ciências Humanas e Sociais - ISSN: 2763-566X Volume 1, número 1, julho-dezembro de 2020.}


Podemos, assim, observar que de forma generalizada, o termo educação foi vinculado à cultura, de modo que, torna-se indispensável tanto às sociedades primitivas como às chamadas civilizadas, deformando o seu sentido e significado específico, sendo considerado, como simplesmente com a função de transmitir técnicas de trabalho e de comportamento, que já se encontram sob o poder do grupo social. Em Morin (2000), o ser humano é singular e múltiplo.

\begin{abstract}
A cultura é constituída pelo conjunto dos saberes, fazeres, regras, normas, proibições, estratégias, crenças, ideias, valores, mitos, que se transmite de geração em geração, se reproduz em cada indivíduo, controla a existência da sociedade e mantém a complexidade psicológica e social. Não há sociedade humana, arcaica ou moderna, desprovida de cultura, mas cada cultura é singular. Assim, sempre existe a cultura das culturas, mas a cultura existe apenas por meio das culturas (2000, p. 56).
\end{abstract}

Neste sentido, os indivíduos são mais do que produtores do processo reprodutor da espécie humana e este mesmo processo é produzido pelos indivíduos a cada geração, continuamente, que, nas suas interações produzem a sociedade e, esta retroage sobre os próprios indivíduos que a criaram. Aí entra a responsabilidade do ensino, uma das funções e objetivos da pedagogia e educação, que não se pode ignorar nesta reflexão. $\mathrm{O}$ 'ensino' é arte/ação de transmitir conhecimentos a um aluno, de modo que ele os compreenda e assimile, e, neste sentido mais restrito, é apenas cognitivo. Cabe ao ensino transmitir conhecimento que nos permita não apenas um mero saber, mas uma cultura que favoreça a compreensão de nossa condição e nos ajude a viver e, ao mesmo tempo, um modo de pensar mais aberto e livre, a nos tornar melhores, mais felizes, a viver a parte poética de nossas vidas (MORIN, 2001) e, certamente, ao exercício do pensar e amar o mundo.

A qualificação docente, fundamental neste processo, consiste "em conhecer o mundo e ser capaz de instruir os outros acerca deste, porém sua autoridade se assenta na responsabilidade que ele assume por este mundo" (ARENDT, 1997, p. 239). E a Pedagogia "ocupa-se, de fato, dos processos educativos, métodos, maneiras de ensinar, mas antes disso ela tem um significado bem mais amplo, bem mais globalizante" (LIBÂNEO, 2004, p. 9).

Nesse sentido, não há outra maneira de se pensar na Pedagogia, senão como "um campo de conhecimentos sobre a problemática educativa na sua totalidade e historicidade e, ao mesmo tempo, uma diretriz orientadora da ação educativa" (p. 9). Libâneo (2001) faz uma crítica à legislação atual para o curso de Pedagogia, especificamente, a Resolução CNE/CP n. 1, de 15 de maio de 2006, que permite a interpretação à construção da identidade profissional do

\footnotetext{
Sertanias: Revista de Ciências Humanas e Sociais - ISSN: 2763-566X Volume 1, número 1, julho-dezembro de 2020.
} 
pedagogo e não traz em pauta a discussão e nem o entendimento da Pedagogia com ciência da educação.

Essa compreensão está também presente na obra de Pimenta, Franco e Libâneo (2007). O entendimento da Pedagogia com múltiplos sentidos, em Libâneo (2006), indica que todo trabalho docente é trabalho pedagógico, mas nem todo trabalho pedagógico é trabalho docente. O pedagógico refere-se "a finalidades da ação educativa, implicando objetivos sociopolíticos a partir dos quais se estabelecem formas organizativas e metodológicas da ação educativa" (LIBÂNEO, 2004, p. 9). Em toda ação educativa deve ser considerada a relação teoria e prática, para assim, produzir sentidos, novos conhecimentos e, nesse processo, exige a ação ativa do sujeito autônomo, consciente, criativo, pesquisador.

Para Imbert (2003), há distinção entre os termos prática e práxis, e questão de diferenciação entre um termo e outro é muito importante, pois,

\footnotetext{
Distinguir práxis e prática permite uma demarcação das características do empreendimento pedagógico. Há, ou não, lugar na escola para uma práxis? Ou será que, na maioria das vezes, são, sobretudo, simples práticas que nela se desenvolvem, ou seja, um fazer que ocupa o tempo e o espaço, visa a um efeito, produz um objeto (aprendizagem, saberes) e um sujeito-objeto (um escolar que recebe esse saber e sofre essas aprendizagens), mas que em nenhum momento é portador de autonomia (IMBERT, 2003, p. 15).
}

Recorrendo à diferenciação do conceito de poíesis e práxis de Carr (1996), como uma forma de caracterizar uma prática pedagógica, Franco (2016, p. 535) entende que, a prática educativa, "de modo amplo, só adquirirá inteligibilidade quando for regida por critérios éticos imanentes". Poíesis, termo de origem grega, formado, como poeta e poema, de poiein, eclodir. Eclodir é 'surgir', 'aparecer', 'vir à luz'. Quando há uma eclosão, algo surge, aparece, vem à luz (FERREIRA, 1996). Portanto, neste sentido, poíesis é o mesmo que poesia e "deve ser compreendida simbolicamente, sem exigir fidedignidade dos conceitos utilizados. Se isso fosse feito, ela perderia sua razão de ser" (1996, p. 203) e, assim, definida como ação humana de compor, construir, produzir. Em Castro (2000), a poética filosófica

define o que é a poíesis a partir da sua concepção de conhecimento e verdade. De outro lado, a poíesis se dá como poética nos poemas dos poetas. Seja na palavra do filósofo ou do poeta, poética e poíesis radicam na questão da interpretação (apud FERREIRA, 2002, p. 200).

Na visão de Franco e Gilberto (2011, p. 217),

O saber pedagógico só pode se constituir a partir do próprio sujeito, que deverá ser formado como alguém capaz de construção e de mobilização de saberes. A grande

\section{Sertanias: Revista de Ciências Humanas e Sociais - ISSN: 2763-566X Volume 1, número 1, julho-dezembro de 2020.}


dificuldade em relação à formação de professores é que, se quisermos ter bons professores, teremos que formá-los como sujeitos capazes de produzir ações e saberes, conscientes de seu compromisso social e político. Não dá para formar professores como objetos dotados de habilidades e competências, instaladas de fora para dentro, sob forma de fazeres descobertos por outros, que nada significam na hora da prática.

Não há dúvida sobre a importância do professor-pesquisador, que deverá ser um sujeito consciente de sua própria prática, e não é inevitável que o empenho em estimular a sua reflexão venha a reforçar o que afirmam os autores (2011) quando se referem à necessidade de tomar a prática docente como uma prática histórica, socialmente organizada. E, devido a suas características e concepção, a atividade prática docente não se circunscreve no visível da prática pedagógica em sala de aula. O que nos leva a pensar que todas as práticas docentes devem ajudar a criar situações e permitir condições ao desenvolvimento e autonomia do professoreducador. Em síntese, a atividade prática docente "não é exterior às condições sociais, emocionais, profissionais e culturais do professor, como também não se realiza unicamente nos procedimentos didático-metodológicos utilizados em sala de aula" (FRANCO; GILBERTO, 2011, p. 218).

Em Fazenda (2002), a formação na educação à, pela e para a interdisciplinaridade se impõe e precisa ser concebida sob bases específicas, apoiadas por trabalhos desenvolvidos na área e estes trabalhos devem ser referendados em diferentes ciências que têm como finalidade contribuir com as particularidades da formação profissional até a atuação do professor. Parte, portanto, do entendimento da Pedagogia como uma ciência e o curso de Pedagogia tem como objetivo a formação do Pedagogo, um sujeito ativo que deve conhecer que o lugar de onde se fala é condição essencial para quem necessita investigar e desenvolver uma prática cotidiana. Na Resolução CNE/CP n. 1/2006, que institui Diretrizes Curriculares Nacionais para o Curso de Pedagogia, licenciatura,

Art. $2^{\circ}$ Compreende-se a docência como ação educativa e processo pedagógico metódico e intencional, construído em relações sociais étnico-raciais e produtivas, as quais influenciam conceitos, princípios e objetivos da Pedagogia, desenvolvendo-se na articulação entre conhecimentos científicos e culturais, valores éticos e estéticos inerentes a processos de aprendizagem, de socialização e de construção do conhecimento, no âmbito do diálogo entre visões de mundo (BRASIL, 2006, p. 1)

Franco (2017) afirma que tem acompanhado a história da pedagogia brasileira há quase cinquenta anos e, nesse percurso, tem buscado compreender os seus caminhos e descaminhos e, continuamente pesquisado práticas e epistemologia da pedagogia, observando a transformação de discursos acerca do fenômeno, em narrativas de suas possibilidades ou de

\section{Sertanias: Revista de Ciências Humanas e Sociais - ISSN: 2763-566X Volume 1, número 1, julho-dezembro de 2020.}


suas fragilidades. Assim, tem buscado interpretar práticas docentes e salas de aula como contingenciadas por diferentes concepções pedagógicas, que se materializam nas práticas, consubstanciadas por teorias, políticas e múltiplas interpretações, que se requerem pelo exercício da práxis. Franco (2017) considera a pedagogia “como uma 'prática teórica', no sentido althusseriano, que a define como uma prática específica que se articula em uma unidade complexa de práticas existentes, em um determinado espaço social” (2017, p. 162). Logo a seguir, justifica a sua preocupação com seguidas provocações sobre o pedagogo e sua prática educativa, a pedagogia como pensamento reflexivo sobre o que ocorre nas práticas educativas e o pensamento crítico que reelabora, corrige, orienta o que deveria ocorrer nas práticas educativas e complementa, questionando:

De que pedagogia falo? Falo das entranhas de sua epistemologia e de sua práxis e vislumbro-a organizando-se como prática social; como conjunto organizado de conhecimentos, como saberes pedagógicos que são os conhecimentos incorporados e interpretados pelos sujeitos e até como curso e/ou disciplina acadêmica que se estrutura para formar pensadores na lógica desta racionalidade pedagógica e que atuem como docentes, ou como pedagogos, pesquisadores, ou como atores sociais (2017, p. 162).

A autora (2017, p. 162) afirma que "os descaminhos da pedagogia se devam à não incorporação desta racionalidade às políticas e práticas que se organizam em torno de processos educativos". Esta é a razão de limitar sua possibilidade de agir adequadamente frente a seu objeto de estudos: as práticas em suas diferentes inserções sociais. Práticas educativas e práticas pedagógicas não são sinônimos, a primeira se refere a "práticas que ocorrem para a concretização de processos educacionais" e, a segunda, "a práticas sociais que são exercidas com a finalidade de concretizar processos pedagógicos. Fala-se, então, de práticas da Educação e práticas da Pedagogia" (2016, p. 536).

Nesse sentido, Carr (1989) também traz importantes contribuições quando pergunta "se pode ser científica a investigação educativa" e provoca novos questionamentos sobre o interesse filosófico na ideia de uma ciência educativa. Esta não é uma ideia nova. Lembra que durante a segunda metade do século XIX, Spencer, Huxley, Bain e outros estudiosos já defendiam que muitos dos problemas intransigentes da educação só poderiam ser resolvidos com a adaptação de métodos experimentais das ciências naturais. Esta é uma discussão que envolve muitas questões sobre o papel da ciência na educação e há uma divisão de opiniões que se divergem. Mas, no seu entendimento, há muitas faces e formas e, dentro da filosofia da educação a disputa tem se referido acerca da concepção de "teoria educativa", inclusive se esta deve se limitar por

\section{Sertanias: Revista de Ciências Humanas e Sociais - ISSN: 2763-566X Volume 1, número 1, julho-dezembro de 2020.}


caminhos de racionalidade puramente científicos e se deve interpretar, mas generosamente, do modo que incorpore outras diversas "formas de conhecimento".

Para Carr (1989), a investigação educativa nos leva a pensar a docência, práticas pedagógicas e educativas com um novo olhar para a formação e atuação do pedagogo e a riqueza do momento do processo de ensinar e aprender e, também educar em direitos humanos. Assim, busca compreender os caminhos que os levam à incorporação de novas tecnologias, práticas pedagógicas, a ousadia para investigar sua própria prática, suas representações docentes, a recuperação de sua memória, tornar-se um sujeito ativo que acompanha e reflete sobre o seu processo evolutivo na educação, apropriando-se de novas formas de pensar a docência e apropriar-se de novas ferramentas educacionais e tecnológicas.

Oliveira (2002, p. 217) diz:

Olhar é um verbo que designa a função atribuída ao olho, órgão da visão, derivando do latim oculus. Cumpre atentar para a relevância da visão à percepção do mundo. Sua hegemonia é tão evidente que muitas vezes chega a arrefecer os demais sentidos. É sobretudo pelo olhar que se constrói a cosmovisão; é pelo olhar que o sujeito se ergue como realizador de sua própria história, como construtor de um novo mundo. E é com este mesmo olhar que se deve atentar para os educadores, num momento tão particular como o da apropriação do instrumental tecnológico e incorporação do mesmo à renovação da sua prática pedagógica.

É através do olhar que se pode ver, descrever o olhar que interpreta e permite passear sobre as coisas do mundo, criticar, espelhar, registrar, perscrutar, investigar e indagar a partir e para além do visto, direcionar e atentar, aflorar certa inquietação, intencionar. Pois, "ver se dá de nós para fora. Olhar é sair de si e trazer o mundo para dentro de si” (GAETA, 2002, p. 223). O que nos permite o olhar? "Ver-avaliar-compreender...perceber-apreender-conhecer...olhar e criar a vontade de olhar mais. É assim que se insere um novo elemento no universo do olhar: o desejo" (p. 224). É uma condição para sentir, perceber o papel do professor-educador, necessária ao seu olhar, repleto de sentidos, significados, sentimentos próprios, um pesquisador de sua própria formação, saberes e práticas docentes.

\section{Pedagogia, relações de saber e gênero na escola}

Por que buscar uma compreensão sobre a pedagogia e suas confluências com as relações de saber e gênero na escola? Estamos vivemos um tempo de expectativas, perplexidades e de crises na educação e, junto a tudo isso, a emergência de novos cenários políticos, econômicos,

\section{Sertanias: Revista de Ciências Humanas e Sociais - ISSN: 2763-566X Volume 1, número 1, julho-dezembro de 2020.}


sociais, culturais, produtivos acenam a dependência da utilização de novos saberes, novos conhecimentos e formas de viver a vida no mundo e direito a ter direitos, uma condição humana.

As ciências têm sido fundamentais no processo de construção do conhecimento sobre categorias que, ao longo da história da humanidade e processo civilizador, são produzidas pelas sociedades e suas contribuições apontam para uma nova forma de perceber as relações de gênero, etnia/raça etc que se interrelacionam. No Brasil, desde o período colonial, essas relações autoritárias, patriarcais, verticalizadas, colonizadoras, constroem desigualdades e exclusão social e a escola não ficou fora disso.

[...] no Brasil a instituição escolar é, primeiramente, masculina e religiosa. Os jesuítas, 'braço espiritual da colonização', para além das tentativas de catequização dos índios, investem, de fato, na formação dos meninos e jovens brancos dos setores dominantes. As primeiras escolas brasileiras regidas por esses irmãos (e a grande maioria daquelas que se organizam a partir de outras ordens religiosas) constituem-se, pois, num espaço marcadamente masculino, voltado para a formação de um católico exemplar. É importante notar que esse modelo de ensino permanece no País por um largo tempo, mesmo depois de oficialmente afastado, ao final do século XVIII (LOURO, 2003, p. 94).

Desse modo, se torna cada vez mais necessário pensar a pedagogia e novas formas de ensinar e aprender na escola e na vida, dotar os cidadãos de competências e capacidades para pensar e desempenhar funções plurais, multidimensionais, transdisciplinar e transversais.

Nesta perspectiva, surge exigências dos níveis de qualificação do profissional da educação e de outras áreas do saber, que devem se confluírem de forma a alargar as interrelações entre os quatro pilares da educação contemporânea, como eixos norteadores da política educacional, com objetivo de aprender a ser, a fazer, a viver juntos e a conhecer, valorizando a importância de constituir aprendizagens indispensáveis e que devem ser perseguidas de forma contínua e permanente pela educação do cidadão (MORIN, 2000).

Assim como todo conhecimento, a Pedagogia comporta o risco do erro e da ilusão e, indissociável da educação, “deve enfrentar o problema de dupla face do erro e da ilusão, sendo que o maior erro seria "subestimar o problema do erro; a maior ilusão seria subestimar o problema da ilusão. O reconhecimento do erro e da ilusão é ainda mais difícil, porque o erro e a ilusão não se reconhecem, em absoluto, como tais" (MORIN, 2000, p. 19). O autor chama atenção para observar que as cegueiras do conhecimento (o erro e a ilusão), constituem-se como o "calcanhar-de-Aquiles" do conhecimento. A educação deve mostrar que não há conhecimento que não esteja, em algum grau, enquadrado nestes termos e ameaçado por eles.

\section{Sertanias: Revista de Ciências Humanas e Sociais - ISSN: 2763-566X Volume 1, número 1, julho-dezembro de 2020.}


O conhecimento não é um espelho das coisas ou do mundo externo. "Todas as percepções são, ao mesmo tempo, traduções e reconstruções cerebrais com base em estímulos ou sinais captados e codificados pelos sentidos" (MORIN, 2000, p. 20). O conhecimento científico não pode tratar sozinho dos problemas epistemológicos, filosóficos, éticos e a educação fica na responsabilidade de identificar a origem de erros, ilusões, cegueiras. A racionalidade é a maior proteção para esta questão, para valorizar o conhecimento complexo e promover a "inteligência geral" dos indivíduos que acontece desde a infância, passando pela adolescência até alcançar a vida adulta.

Nesse sentido, há uma questão que merece destaque nesta questão. Refere-se às "pedagogias culturais em circulação" e de que modo elas têm afetado o currículo, as relações entre professor- aluno na sala de aula, produzido "tias e tiazinhas" e quais as narrativas que têm sido construídas nos diversos textos culturais (músicas, filmes, novelas, comerciais, programas infantis etc.) sobre classe social, raça, etnia, infância, relações de gênero, sexualidade e relações afetivas de modo geral (FELIPE, 2000).

Gênero, um termo polissêmico, plural. No "Relatório da Comissão Mundial de Cultura e Desenvolvimento: Nossa diversidade criadora" (CUÉLLAR et al, 1997, p. 169), gênero "é uma questão existencial que constitui preocupação central em todas as culturas - as outras são as relações de parentesco e a morte". Gênero é relacionado ao termo cultura, no qual, a interpretação cultural do gênero é elemento central à identidade de cada indivíduo, considerando a definição de identidade por uma rede de relacionamentos na qual o indivíduo está integrado desde seu nascimento, e a definição de sexo desempenha papel central. Reconhece as questões ligadas à dominação, portanto, de poder, como tema fundamental à compreensão da questão de gênero em um mundo em transformação.

Silva (2000) destaca que as questões acerca do multiculturalismo e da produção social da diferença, tornaram-se, nos últimos anos, centrais na teoria educacional crítica e até mesmo nas pedagogias oficiais. As identidades sexuais e de gênero estão continuamente se constituindo e se transformando e a participação da escola na diferença é preocupante. O que mais preocupa é que "mesmo tratadas de forma marginal como 'temas transversais', essas questões são reconhecidas, inclusive pelo oficialismo, como legítimas questões de conhecimento" (2000, p. 73). Esse processo na escola, traz um problema sério e causa estranheza nas discussões, principalmente pela ausência de uma teoria da identidade e da diferença.

Sertanias: Revista de Ciências Humanas e Sociais - ISSN: 2763-566X Volume 1, número 1, julho-dezembro de 2020. 
Louro (2003, p. 28) observa que, em suas relações sociais,

atravessadas por diferentes discursos, símbolos, representações e práticas, os sujeitos vão se construindo como masculinos ou femininos, arranjando e desarranjando seus lugares sociais, suas disposições, suas formas de ser e de estar no mundo. Essas construções e esses arranjos são sempre transitórios, transformando-se não apenas ao longo do tempo, historicamente, como também transformando-se na articulação com as histórias pessoais, as identidades sexuais, étnicas, de raça, de classe ...

A Pedagogia, na observação de Felipe (2000, p. 167), tem sido vista como

um conjunto de estratégias que devem ser postas em prática na tentativa de ensinar conteúdos específicos. Da mesma forma, o currículo, em sua visão mais tradicional, tem se colocado como uma listagem de conteúdos, nos quais a criança precisaria adquirir determinadas habilidades, especialmente em se tratando da educação infantil (2000, p. 167).

Felipe (2000, p. 167) recorre a Giroux e McLaren (1995, p. 144) para dizer que há pedagogia em qualquer lugar ou situação onde o conhecimento seja produzido, "em qualquer lugar em que existe a possibilidade de construir verdades, mesmo que estas verdades pareçam irremediavelmente redundantes, superficiais e próximas ao lugar comum”. Desse modo, os diferentes contextos sociais e educacionais presentes na atualidade fazem circular as concepções de gênero, raça, etnia, sexualidade, classe social, etc. Pesquisadores de diferentes áreas do saber, ao longo do tempo, vêm se preocupando com esta discussão acerca das práticas e da docência na escola e, muitos deles têm se dedicado ao estudo e combate às práticas autoritárias, que desde o Brasil colônia, vem (re)produzindo racismo, machismo, homofobias, violências, que se acirram na sociedade e na escola. O pedagogo é o profissional que tem a formação para o exercício da docência na Educação Infantil e anos iniciais do Ensino Fundamental, um profissional que deve estar preparado para atuar em espaços escolares e nãoescolares, na educação formal, não formal e informal.

No Art. $2^{\circ}$ da Resolução n. 1/2006, as Diretrizes Curriculares para o curso de Pedagogia aplicam-se à formação inicial para o exercício da docência na Educação Infantil e nos anos iniciais do Ensino Fundamental, nos cursos de Ensino Médio, na modalidade Normal, e em cursos de Educação Profissional na área de serviços e apoio escolar, bem como em outras áreas nas quais sejam previstos conhecimentos pedagógicos (BRASIL, 2006, p. 1).

A educação, um processo contínuo, permanente, inicia-se na infância, primeiro no âmbito familiar e, em seguida, a criança passa a frequentar a escola, lugar destinado a desenvolver interações, fomentar a sociabilidade entre alunos, um espaço que se define como vida, de diálogo, ternura, para pensar, mas, curiosamente, tem se revelado como espaço de contradições, estratégia e discursos de poder-saber (FOUCAULT, 2003).

\section{Sertanias: Revista de Ciências Humanas e Sociais - ISSN: 2763-566X Volume 1, número 1, julho-dezembro de 2020.}


A Pedagogia é muito importante quando tem capacidade de trabalhar com a interdisciplinaridade, transversalidade, complexidade, no currículo, práticas docentes, pedagógicas, metodologias, didática e fornecer conhecimentos necessários no combate à ignorância sobre conceitos/concepções de gênero, raça/etnia e outros marcadores que são empregados nos discursos, geram preconceitos.

Franco (2017) reafirma o caráter eminentemente político da Pedagogia e a intenção acerca desta questão, que coloca essa ciência, entre "insistências e resistências", buscando realçar "que a reflexão e a crítica são movimentos essenciais à compreensão do fenômeno educativo e que a não consideração dessas especificidades tem produzido o esgotamento da racionalidade pedagógica" (p. 161). Esse esgotamento vem abrindo brechas que geram dúvidas, o que pode trazer e tem trazido fortes abalos às possibilidades de uma prática educativa crítica e comprometida que pode se originar da experiência, da técnica e da aplicação da teoria, que se apresenta no discurso, diálogo, conversação, investigação, pesquisa.

Assim, trazer um compromisso político-social, uma intencionalidade, um ato pedagógico, a partir da intenção comprometida com o saber-fazer consciente e responsável. Enfim, uma práxis com sentido ético.

A pedagogia é ou deveria ser o pensamento reflexivo sobre o que ocorre nas práticas educativas; ao mesmo tempo em que é, ou deveria ser, o pensamento crítico que reelabora, corrige e orienta o que deveria ocorrer nestas práticas educativas. A pedagogia, como conhecimento científico e como prática social, precisa compreender o que ocorre nas práticas e a partir desta compreensão, vislumbrar o que precisa ocorrer. A pedagogia circula na íntima articulação entre o que é e o que pode ser; entre o pensamento reflexivo e o crítico (FRANCO, 2017, p. 161).

A característica fundamental que sustenta a concepção da Pedagogia como pensamento reflexivo, permite ao pedagogo agir, conhecer, transformar seu espaço de atuação, provocar mudanças com consciência e responsabilidade. Por isso, uma atuação ética, ação coerente e transformadora da prática pedagógica, incorporadas de sentimentos, é capaz de produzir pensamento autônomo, favorecer a formação de um ser criativo, a cidadania, a emancipação e a condição humana. É necessário ter em conta que as relações de saber e poder na escola precisam ser questionadas.

Recorrendo a Foucault (2003a, 2003b) e a Louro (2003) é possível entender que o poder disciplinar se constitui através das práticas cotidianas, das técnicas silenciosas, de dispositivos de poder, os sujeitos.

Homens e mulheres certamente não são construídos apenas através de mecanismos de repressão ou censura, eles e elas se fazem, também, através de práticas e relações que

\footnotetext{
Sertanias: Revista de Ciências Humanas e Sociais - ISSN: 2763-566X Volume 1, número 1, julho-dezembro de 2020.
} 
instituem gestos, modos de ser e de estar no mundo, formas de falar e de agir, condutas e posturas apropriadas (e, usualmente, diversas). Os gêneros se produzem, portanto, nas e pelas relações de poder (LOURO, 2003, p. 41).

As relações de saber na escola têm sido criticadas há muitas décadas, inclusive sobre relações de gênero e intersecções com raça, etnia, classe social, escolarização etc, e a rede de poder que permeia esta questão de gênero, favorece a compreensão de que os gêneros se produzem na e pelas relações de poder, definidas por Foucault, como formas de domínios de saber a partir de práticas sociais, que na sua concepção podem chegar a engendrar domínios de saber

que não somente fazem aparecer novos objetos, novos conceitos, novas técnicas, mas também fazem nascer formas totalmente novas de sujeitos e de sujeitos de conhecimento. O próprio sujeito de conhecimento tem uma história, a relação do sujeito com o objeto, ou, mais claramente, a própria verdade tem uma história (2003a, p. 8).

Louro (1997) trata da emergência do conceito de "gênero", sua distinção e relações com referência a sexo, sexualidade, destacando as intricadas redes de poder em que essas e outras categorias como raça, etnia, estão implicadas e observa nessa relação, quem é "diferente" e a participação da escola na produção das diferenças, tendo com aporte teórico os Estudos Culturais, Estudos Negros, Estudos Gays e lésbicos.

Nesse percurso, a autora atenta-se para as representações de professoras (es) no espaço escolar, analisa iniciativas pedagógicas feministas e propostas de "educação sexual”, chega a considerações de que o campo de estudos de gênero e sexualidade é marcadamente político, contemporâneo, instável e, em constante construção teórica e metodológica, exige autoquestionamento e subversão de paradigmas científicos.

\section{Considerações Finais}

As práticas pedagógicas devem demonstrar consciência da diversidade, respeitar as diferenças de gênero, bem como outras decorrentes de marcadores sociais de natureza étnicoracial, classes sociais, escolhas sexuais, entre outras, estabelecendo diálogo entre a área educacional e as demais áreas do conhecimento.

Portanto, todos devem, igualmente, poder se beneficiar de conhecimentos pertinentes às categorias de gênero, raça/etnia, classe social, etc, para responder às necessidades fundamentais do homem, tanto em relação à aprendizagem escolar como conteúdos educativos essenciais ao

\footnotetext{
Sertanias: Revista de Ciências Humanas e Sociais - ISSN: 2763-566X Volume 1, número 1, julho-dezembro de 2020.
} 
combate aos (pre)conceitos, à discriminação, desigualdades e exclusão de gênero e seas intersecções com outros marcadores sociais na escola e sociedade.

Para tanto, o estudante de Pedagogia, conforme Art. $3^{\circ}$, da Resolução CNE/CP n.1/2006, precisa vivenciar experiências e conhecimentos através do trabalho com um repertório de informações e habilidades, composto por pluralidade de conhecimentos teóricos e práticos, a partir de diversas vivências de aprendizagens, cuja consolidação deverá acontecer no exercício da profissão. Para tanto, os conhecimentos e saberes do pedagogo deverá ser fundamentado em princípios de interdisciplinaridade, contextualização, democratização, pertinência e relevância social, ética e sensibilidade afetiva e estética.

Além disso, é central à formação do Pedagogo, o conhecimento da escola como organização complexa que tem a função de promover a educação para a cidadania, emancipação e direitos humanos, a pesquisa, a análise e a aplicação dos resultados de investigações de interesse da área educacional, produzir e difundir conhecimento científico-tecnológico do campo educacional, em contextos escolares e não-escolares.

Enfim, o profissional professor, o pedagogo, deve atuar com ética e compromisso com vistas à construção de uma sociedade justa, equânime, igualitária, com direito a ter direitos, fortalecer oportunidade de escolarização, identificar problemas socioculturais e educacionais com posturas investigativa, integrativa e propositiva em face de realidades complexas com objetivo de contribuir para superação de exclusões sociais, étnico-raciais, econômicas, culturais, religiosas, políticas e outras.

\section{Referências}

ABBAGNANO, Nicola. Dicionário de Filosofia. São Paulo: Martins Fontes, 2003.

ARENDT, Hannah. Entre o passado e o futuro. 4 ed. Trad. Mauro W. Barbosa de Almeida. São Paulo: Perspectiva, 1997.

BRASIL. Conselho Nacional de Educação. Conselho Pleno. Resolução CNE/CP n. 1, de 15 de maio de 2006. Diretrizes Curriculares Nacionais para o Curso de Graduação em Pedagogia, Licenciatura. Brasília, 2006. Disponível em: <http://portal.mec.gov.br/cne/arquivos/pdf/rcp01_06.pdf> Acesso:12 ago.2020

CARR, Wilfred. Una teoria para la educación: hacia una investigación educativa crítica. Madrid: MORATA, 1996.

CARR, Wilfred. Quality in teaching. London: Falmers Press,1989.

Sertanias: Revista de Ciências Humanas e Sociais - ISSN: 2763-566X Volume 1, número 1, julho-dezembro de 2020. 
CARR, Wilfred; KEMMIS, Sthephen. Teoría crítica de la enseñanza: la investigaciónacción en la formación del profesorado. Barcelona: Ediciones Martínez Roca, 1988.

CUÉLLER, Javier Pérez de (Org.). Nossa Diversidade Criadora: Relatório da Comissão Mundial de Cultura e Desenvolvimento. Trad. Alessandro Warley Candeas. Campinas, SP: Papirus; Brasília: UNESCO, 1997.

FAZENDA, Ivani. Construindo aspectos teórico-metodológicos da pesquisa sobre Interdisciplinaridade. In: FAZENDA, Ivani (Org.). Dicionário em construção: interdisciplinaridade. São Paulo: Cortez, 2002. p. 11-29.

FERREIRA, Maria Elisa de Mattos Pires. Interdisciplinaridade como poíesis. Tese (Doutorado). Pontificia Universidade de São Paulo - PUC. São Paulo, 1996.

FERREIRA, Maria Elisa de Mattos Pires. Poíesis. In: FAZENDA, Ivani (Org.). Dicionário em construção: interdisciplinaridade. São Paulo: Cortez, 2002. p. 200-203.

FELIPE, Jane. Entre as tias e tiazinhas: pedagogias culturais em circulação. In: SILVA, Luiz Heron da (Org.). Século XXI: Qual conhecimento? Qual currículo? Petrópolis, RJ: Vozes, 2000. p. 167-179.

FOUCAULT, Michel. A verdade e as formas jurídicas. 3 ed. Trad. Roberto Cabral de M. Machado e Eduardo J. Morais. Rio de Janeiro: NAU Editora, 2003a.

FOUCAULT, Michel. Estratégia, poder-saber. Trad. Vera Lucia A. Ribeiro. Rio de Janeiro: Forense Universitária, 2003b.

FRANCO, Maria Amélia do Rosário. Pedagogia: por entre resistências e insistências. In: Revista Espaço do Currículo, João Pessoa, v.10, n.2, p. 161-173, maio/ago. 2017.

FRANCO, Maria Amélia do Rosário. Práticas pedagógicas e docência: um olhar a partir da epistemologia do conceito. In: Revista Brasileira de Estudos Pedagógicos. Brasília, v. 97, n. 247, p. 534-551, set./dez. 2016.

FRANCO, Maria Amélia do Rosário. Pedagogia como ciência da Educação. 2.ed. São Paulo: Cortez, 2008.

FRANCO, Maria Amélia do Rosário; GILBERTO, Irene Jeanete Lemos. A prática docente e a construção dos saberes pedagógicos. In: Revista Teias. Ética, Saberes \& Escola, v.12, n. 25, p. 212-224, maio/ago. 2011.

FRANCO, Maria Amélia do Rosário; LIBÂNEO, José Carlos; PIMENTA, Selma Garrido. Elementos para a formulação de diretrizes curriculares para cursos de Pedagogia. Cadernos de Pesquisa, v. 37, n.130, p.63-97, jan./abr. 2007.

GAETA, Cecília. Olhar. In: FAZENDA, Ivani (Org.). Dicionário em construção:

Sertanias: Revista de Ciências Humanas e Sociais - ISSN: 2763-566X

Volume 1, número 1, julho-dezembro de 2020. 
interdisciplinaridade. 2 ed. São Paulo: Cortez, 2002. p. 222-224.

IMBERT, Francis. Para uma praxis pedagógica. Brasília: Plano Editora, 2003.

LIBÂNEO, José Carlos. Pedagogias e pedagogos: inquietações e buscas. Educar, Curitiba, n. 17 , p. $153-176,2001$

LOURO, Guacira Lopes. Gênero, sexualidade e educação: uma perspectiva pósestruturalista. Petrópolis, RJ: Vozes, 1997.

MARTINS, Maria Anita Viviani. Educação. In: FAZENDA, Ivani (Org.). Dicionário em construção: interdisciplinaridade. São Paulo: Cortez, 2002. p. 242-246.

MORIN, Edgar. A cabeça bem-feita: repensar a reforma, reformar o pensamento. Trad. eloá Jacobina. Rio de Janeiro: Bertrand Brasil, 2001.

MORIN, Edgar. Os sete saberes necessários à educação do futuro. Trad. Catarina Eleonora F. da Silva e Jeanne Sawaya. São Paulo: Cortez; Brasília: UNESCO, 2000.

OLIVEIRA, Lucila Maria Pesce de. Olhar. In: FAZENDA, Ivani (Org.). Dicionário em construção: interdisciplinaridade. São Paulo: Cortez, 2002. p. 217-218.

SAVIANI, Dermeval. O pensamento pedagógico brasileira: da aspiração à ciência sob suspeição. Revista Educação e Filosofia, v.21, n.42, p.13-35, jul-dez, 2007.

SILVA, Tomaz Tadeu da. A produção social da identidade e da diferença. In: SILVA, Tomaz Tadeu da (Org.). Identidade e diferença: a perspectiva dos Estudos Culturais. Petrópolis, RJ: Vozes, 2000.

SUSHODOLSKY, Bogdan. A Pedagogia e as grandes correntes filosóficas. Lisboa: Livros Horizontes, 1978.

Sertanias: Revista de Ciências Humanas e Sociais - ISSN: 2763-566X

Volume 1, número 1, julho-dezembro de 2020. 